\title{
ULTRASONOGRAPHIC FINDINGS OF SOME OCULAR AFFECTIONS IN DOGS
}

\author{
RAGAB, G.A. and FATHY, M.Z. \\ ${ }^{1}$ Surgery, Anesthesiology and Radiology Dept., Faculty of Veterinary Medicine, \\ Beni-Suef Univ., Beni-Suef 62511, Egypt.
}

Received: 13 March 2018; Accepted: 18 April 2018

\begin{abstract}
Ultrasonography is easily, safe and non-invasive method which can be used in examination and diagnosis of ocular affections which could not be diagnosed by naked eye such as cataract and intra-ocular hemorrhage. Ultrasonography is considered as the only method for imaging the most segments of the eye globe when the light-conducting media are opaque. In this study, twenty dogs with ocular affections were examined by eye ultrasonography of a $10 \mathrm{MHz}$ micro-convex probe. The results revealed that four cases had thin hyper-echoic lines of the lens indicating early cataract changes, three cases had thin hyper-echoic rims around the lens suggestive of cortical cataract were done. There was one case of aphakia, which characterized by absence of the hyper-echoic posterior lens capsule. Five cases of retinal detachment were detected and by ultrasonography, they appeared as hypo-echoic mass in an-echoic vitreal body. Swelling in the cornea which appeared in three cases of glaucoma and the swelling appeared as an-echoic area in front to the anterior chamber. One case of hypopyon was appeared as a hyper-echoic mass in the anterior chamber. One case of keratitis which appear as hyper-echoic spot in cornea. Two cases of severe iridocyclitis were noticed as the pupil appeared constricted with increased hyper-echoic, proliferated, thickening of the ciliary body. In conclusion, ultrasonography of the eye is a safe, rapid, non-invasive and reliable method for diagnose almost eye affections. The $10 \mathrm{MHz}$ probe gave excellent quality real-time images of posterior chamber and vitreous body.
\end{abstract}

Key words: Dogs, Ultrasonography, ocular affections.

\section{INTRODUCTION}

The eye is only organ responsible for vision in all creatures. It is designed to function like a camera to absorb and reflect the light. The light is directed to the retina and electro-chemical impulses are sent through complex neural pathways via the optic nerve to the visual cortex, where nerve signal is convert to a visual image (Gelatt et al., 2013).

The use of diagnostic veterinary ocular ultrasonography was first reported by Rubin and Koch (1968), and currently is considered as a rapid, non-invasive modality that provides a detailed view of the intraocular components and soft tissues surrounding the orbit (Ramirez and Tucker, 2004; Potter et al., 2008).

Eye is a very attainable organ and non-invasive techniques could be used for diagnosing the diseases that affecting different parts of the eye. However, the eye is also very sensitive organ that could be affected

Corresponding author: Dr. FATHY, M.Z.

E-mail address: mzfhussein83@gmail.com

Present address: Surgery, Anesthesiology and Radiology Dept., Faculty of Veterinary Medicine, Beni-Suef Univ., Beni-Suef 62511, Egypt. if other parts of the body were diseased (Mellersh, 2014).

Ultrasonography is useful for ocular examination inanimals because it is ready, available, not expensive, safe, and non-invasive and couldbe performed with local analgesic eye drops (Mettenleiter, 1995; Ramirez and Tucker, 2004; Boroffka, et al., 2007 and Dietrich, 2007). The diagnostic value of ultrasonography is directed to the observation and assessment of intra-ocular structures of eyes for diagnoses and prognoses and for planning of treatments (Gonzalez et al., 2001; Penninck et al., 2001; Hoffmann et al., 2004a; Ramirez S. Tucker, 2004 and Book et al., 2008).

Structures that cannot be observed by use of routine ophthalmologic examination techniques, such as ciliary bodies or retrobulbarspaces, could be evaluated via ultrasonography (Wilkie and Gilger, 1998; Hoffmann et al., 2004 ). The ultrasonographic appearances of normal and some ocular affection of horses, dogs, and cats have been reported (Spaulding, 2008; Boroffka, 2011 and Gilger and Stoppini, 2011). Ultrasonography is considered as a valuable method for clinical assessment of various ocular and orbital diseases. (Tavana and Peighambarzadeh, 2014). 
In general, the boundaries that reflect sound waves in the eye are; the anterior and posterior corneal surfaces; the anterior and posterior lens capsule and the sclero-retinal rim (Osuobeni and Hamidzada, 1999). The intraocular components of the eye develop in a co-ordinated manner such that an excess in the dimension of one component is counter balanced by a reduction adjustment in another (Wilkie and Colitz, 2009 and El-Tookhy et al., 2012).

The eyeball's fluid content and its superficial position makes it ideally suited for ultrasonography examination. Ocular ultrasound is an technique for imaging the eye and is especially valuable for detection and evaluation retrobulbar and intraocular lesions (Fielding, 2001).

The aim of this study is using of ultrasonography for detection the different intraocular affections which a combined with other ocular diseases that they could be diagnosed by naked eye.

\section{MATERIALS AND METHODS}

This study was conducted on twenty dogs (golden retriever, Bug, Rottweiler and Balady) and aged from one to five years with ocular affections. All animals were examined at surgery, anesthesiology and radiology department, Faculty of Veterinary Medicine, Beni-Suef University. Case history was recorded based on their owners' knowledge. This was followed by ultrasonographic examination. All animals were handled according to the Laboratory Animal Control Guidelines, which basically conform to the Guide for the Care and Use of Laboratory Animals of the National Institutes of Health in the USA (NIH publications No. 86 to 23, revised 1996).

Ultrasonography for ocular examination was done under the effect of tranquilizer Xylazine/HCL $1 \mathrm{mg} /$ $\mathrm{kg}$ (Xyla-Ject 2\% ADWIA Co., A.R.E.) (Torad, 2000) and the animal head was firmly held, and the eyelids were spaced out and put six drops of local analgesic drug Benox (Benoxinate hydrochloride $0.4 \%$, E.I.P.I.CO., Tenth of Ramadan City, Egypt) then the ultrasound gel was applied to coupling the transducer with the cornea.

Ultrasonographic examination was performed using a B-mode ocular ultrasound unit (Sono scape A6
Tokyo, Japan) equipped with a $10.0 \mathrm{MHz}$ microconvex transducer. The structures of the globe were evaluated to a depth of 2-4 cm (Whitcomb, 2002). Ocular abnormalities were evaluated in respect to location (i.e., anterior/posterior segment) and echo texture (Iso-echoic or hypo/hyper-echoic) compared to the surrounding tissues. The transducer was placed directly on the cornea after spreading the coupling gel. Light pressure was applied to maintain good contact between the transducer and the cornea. Each eye was examined in horizontal section with the ultrasound beam running from the medial to the lateral canthi. After ultrasound examination, coupling gel was carefully wiped from the eyes by normal saline. All images were digitally recorded and those views analyzed which gave the maximum information.

\section{RESULTS}

In the present study, alldogs' eyes were scanned by ultrasonography. In each case, a representative sonogram using $10.0 \mathrm{MHz}$ was obtained first. Various ocular affections were detected ultrasonographically such as one case of Keratitis, one case of hypopyone, three cases of bulging in the cornea in case of glaucoma, two cases of iridis, one case of aphakia, seven cases of cataract changes and five cases of retinal detachments. Ultrasonographic appearance of normal eye structure in dog (Fig. 1). Dogs with Keratitis were observed as a hyper-echoic spot present in the cornea a combined with retinal detachment (Fig. 2). Hypopyone was noticed and appeared as hyper-echoic mass filled the anterior chamber (Fig. 3). The cilliary body appeared increase in size, proliferated and misshaped and increases in its echogenicity (Fig. 4). Also, the iris appeared increase in size and misshaped and increases in its echogenicity (Fig. 5). Dogs with early cataract changes, had hyper-echoic lines within the lens, and the strong hype-rechoic curvilinear line was a posterior specular reflection on the surface of the lens (Fig.6\&7). In cortical cataracts, the anterior and posterior cortices were echogenic and the entire capsule was apparent (Fig.8\&9). Aphakia was observed and appeared as an - echoic globe a combined with retinal detachment showing a typical "morning glory" sign in a longitudinal plane attached to the optic disc and the retinal membrane was typically thicker and more echogenic (Fig.10). 


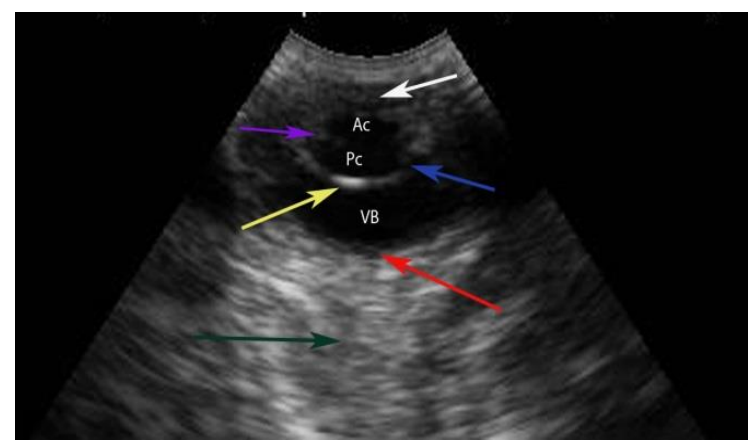

Fig. (1): Ultrasonographic appearance of normal eye showing Cornea (white arrow), Anterior chamber (AC). iris (mouv arrow), Posterior chamber (PC), Cilliary body (blue arrows), Posterior lens capsule (yellow arrow), Vitrous body (VB), Retina (red arrow), and Optic nerve (green arrow)

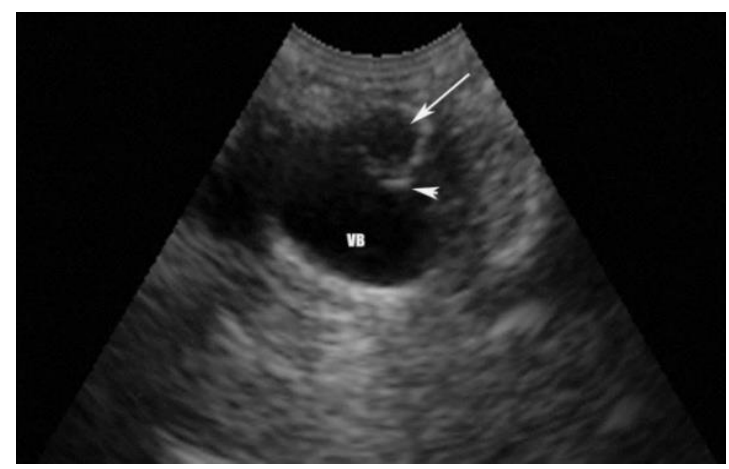

Fig. (3): Ultrasonography image $(10 \mathrm{MHz}$ microconvex probe) showing hypopyone and increase echogenicity of anterior and posterior chamber (white arrow), posterior lens capsule (white head arrow), Vitrous body (VB)

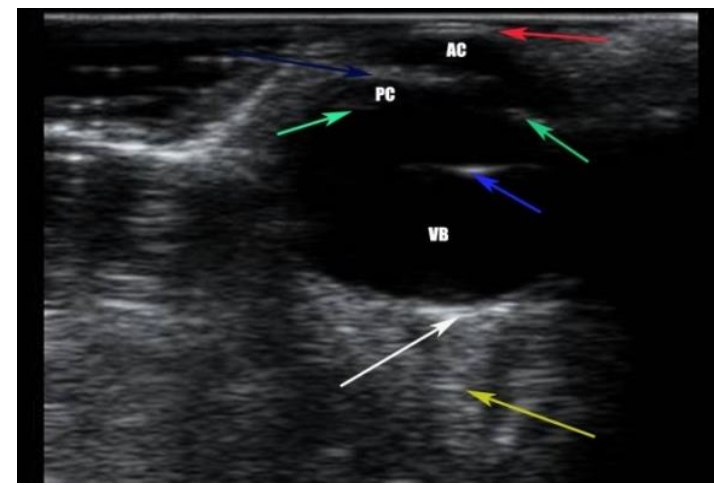

Fig. (5): In case of iridis, Ultrasonography image (10 $\mathrm{MHz}$ micro-convex probe) showing increase of echogenicity of the iris (black blue arrow), Retina (white arrow), Optic nerve (yellow arrow) and Cornea (red arrow), posterior lens capsule (blue arrow), Cilliary body (two green arrows), Vitrous body (VB), Posterior chamber (PC) and Anterior chamber (AC).

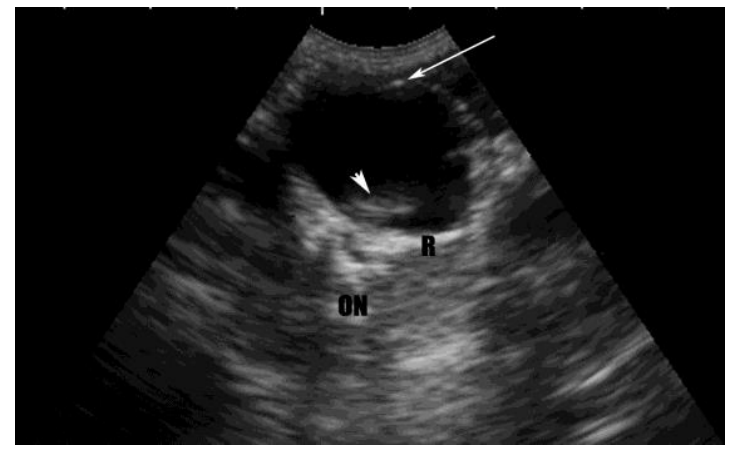

Fig. (2): Ultrasonography image (10 MHz microconvex probe) showing partial retinal detachment (white head arrow), retina (R), optic nerve (ON) and hyper-echoic spot in cornea (keratitis) (white head arrow)

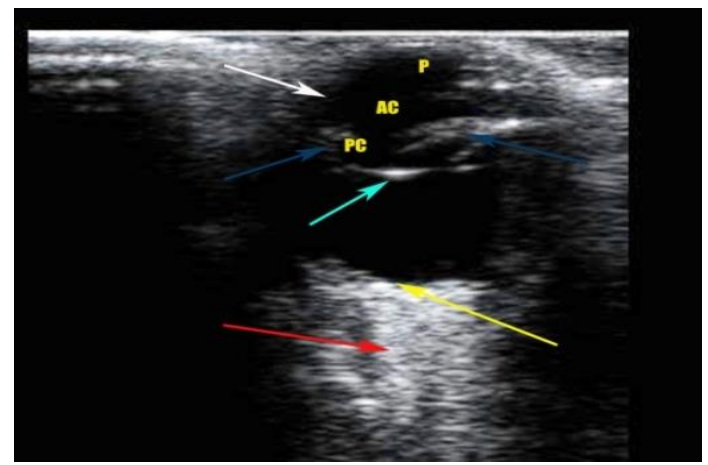

Fig. (4): In glaucoma, ultrasonography image (10 $\mathrm{MHz}$ micro-convex probe) showing misshaping, increase of size and echogenicity of the iris Cilliary body (two black blue arrow), Retina (yellow arrow), Optic nerve (red arrow) and Cornea (white arrow), posterior lens capsule (green arrow), Posterior chamber (PC) and Anterior chamber $(\mathrm{AC})$, plugging in the cornea $(\mathrm{P})$

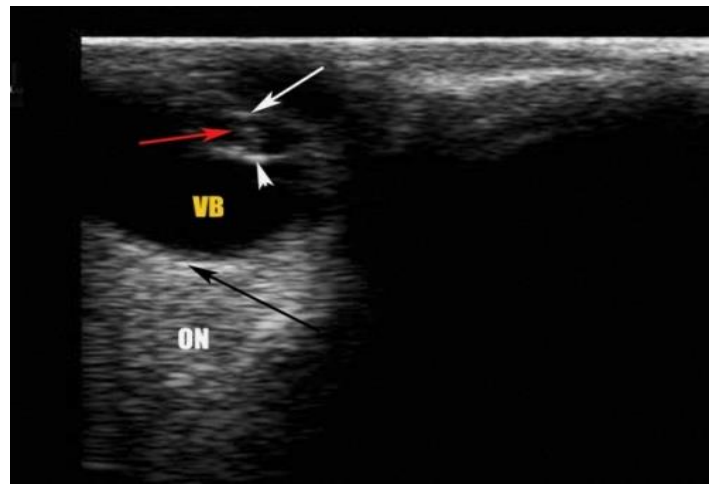

Fig. (6): Ultrasonography image (10 MHz microconvex probe) showing increase of echogenicity of the body of lens as beginning of cataract (red arrow), Retina (black arrow), Optic nerve (ON), anterior lens capsule (white arrow), posterior lens capsule (white head arrow), Vitrous body (VB) 


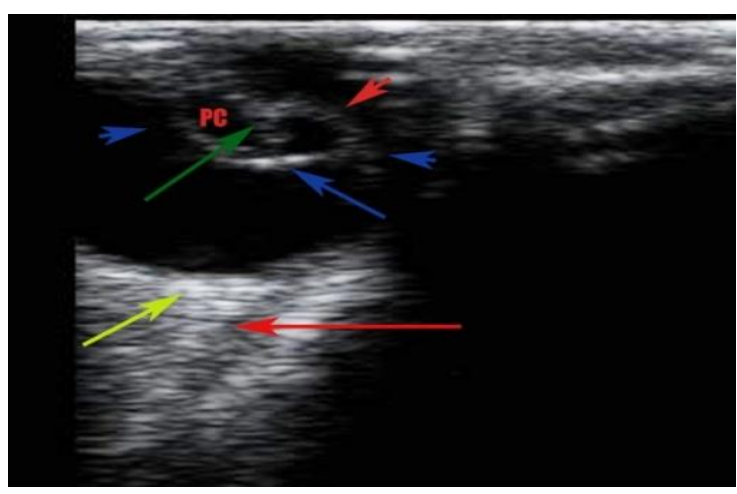

Fig. (7): In case of iridis, Ultrasonography image (10 $\mathrm{MHz}$ micro-convex probe) showing hyper proliferation and increase of echogenicity of the iris (green arrow), Cilliary body (two blue black head arrows), Retina (yellow arrow), Optic nerve (red arrow) and posterior lens capsule (blue arrow), Posterior chamber (PC)

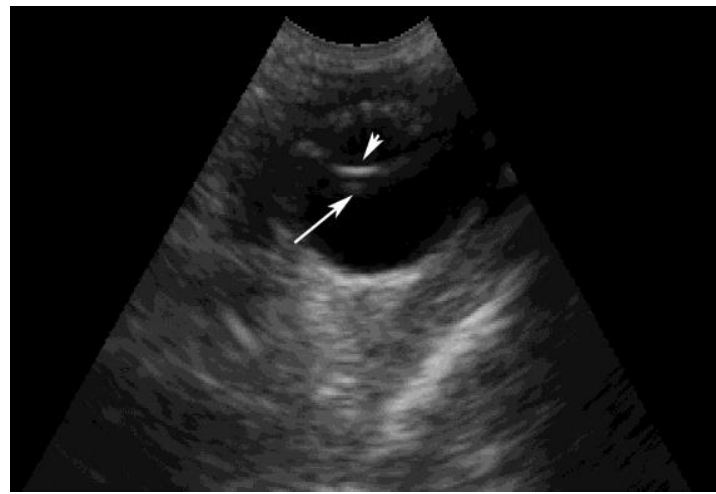

Fig. (9): Cataract appeared at posterior lens capsule (white head arrow) reflex shadow (white arrow)

\section{DISCUSSION}

Ultrasonographic evaluation of the eye is somewhat a recent addition to usual ophthalmic diagnostic examinations in animals but ocular ultrasound is not a replacement for routine ophthalmic examinations (Reef, 1998 and Gonzlez et al., 2001). Results of the present study suggested that the ability of ultrasonography for diagnosis of varies ocular affections. This is in agreement with (Gallhoefer et al., 2013).

Ocular ultrasound has also been helpful in the diagnosis of intraocular affections where routine ophthalmic examinations could not determine the extent of involvement, this in correlation with (Whitcomb, 2002). Results of the present study indicated that the ocular ultrasound is useful to diagnose some diseases and its associated abnormality which cannot detected by naked eye such as glaucoma which diagnosed by tonometer but this

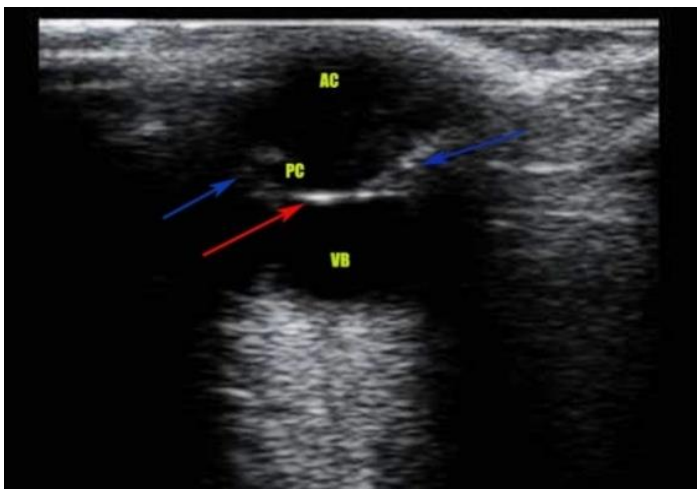

Fig. (8): Ultrasonography image (10 MHz microconvex probe) showing beginning of cataract (red arrow), Vitrous body (VB), Posterior chamber (PC) and Anterior chamber (AC), Cilliary body (two blue black arrows)

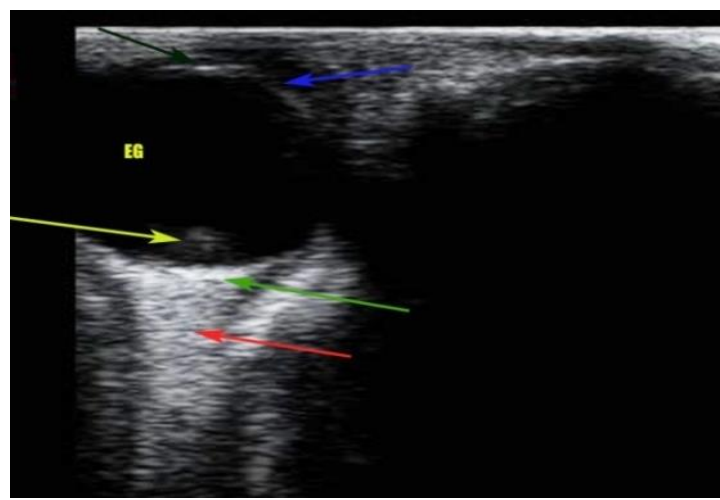

Fig. (10): Ultrasonography image (10 MHz microconvex probe) showing an-echoic eye globe (EG) with Aphakia, partial retinal detachment (yellow arrow), cornea (blue arrow) and hyper-echoic spot at the cornea (dark green arrow). Retina (green arrow), Optic nerve (red arrow)

case was accompanied with retinal detachment which cannot diagnosed except by ocular ultrasound. Thisis in correlation with (Gonzalez et al., 2001 and Gallhoefer et al., 2013).

The result showed that hyper-echoic mass in anterior chamber. This is in correlation with (El-Tookhy and Tharwat, 2013) they mentioned that hypopyon was seen as hyper-echoicshadow in the anterior chamber. Also, the result of the present study showed iridis which appeared as increase in size, proliferated and misshaped and increases in its echogenicity of cilliary body. This is in agreement with (El-Tookhy and Tharwat, 2013) they reported that iridis was seen as thickening of the ciliary body and increased in its echogenicity.

Cataracts are the most frequent intra-ocular lesion that presentin small animals and it considered as a common cause of vision loss. The presence of cataracts impairs ophthalmoscopic evaluation of the 
vitreous and fundus. Thus, ultrasonographic examination prior to cataract surgical removal is indicated to evaluate other intra-ocular abnormalities that may influence surgery outcome. Cataract formation is easy to image by ultrasound, as an increase of echogenicity is appreciated in the normally anechoic lens, this is in agreement with (Gelatt and Mackay, 2005; Spaulding, 2008 and Williams, 2010) reported that the echogenicity, size and shape of the lens may change with duration and type of cataract.

Retinal detachment is sometimes detected when cataracts are present and should always be looked for when a diagnosis of cataracts is made. The prevalence of retinal detachment most frequently observed in eyes with maturity of cataract and glaucoma. This is in correlation with (McLeod et al., 1977; Gonzalez et al., 2001 and Dar, et al., 2014). In conclusion, ultrasonography of the eye is a safe, rapid, noninvasive and reliable method for diagnose almost eye affections. The $10 \mathrm{MHz}$ probe gave good quality realtime images of posterior chamber and vitreous body.

Conflict of interest

None declared.

\section{REFERENCES}

Book, B.; Van der Woerdt, A. and Wilkie, D.A. (2008): Ultrasonographic abnormalities in eyes with traumatic hyphema obscuring intraocular structures: 33 cases (1991-2002). J. Vet. Emerg Crit Care; 18:383-387.

Boroffka, S.A. (2011): Eyes. In: Barr F, Gaschen L, eds. BSAVA manual of canine and feline ultrasonography. Gloucester, England: British Small Animal Veterinary Association; 183192.

Boroffka, S.A.; Verbruggen, A.M. and Grinwis, G.C. (2007): Assessment of ultrasonography and computed tomography for the evaluation of unilateral orbital disease in dogs. J. Am. Vet. Med. Assoc; 230:671-680.

Dar, M.; Tiwari, D.K.; Patil, D.B. and Parikh, P.V. (2014): B-scan ultrasonography of ocular abnormalities: a review of 182 dogs. IJVR, Vol. 15, No. 2, Ser. No. 47, Pages 122-126.

Dietrich, U.M. (2007): Ophthalmic examination and diagnostics part 3: diagnostic ultrasonography. In: Gelatt KN, ed. Veterinary ophthalmology. $4^{\text {th }}$ ed. Ames, Iowa: Blackwell; 507-519.

El-Tookhy, O. and Tharwat, M. (2013): Clinical and ultrasonographic findings of some ocular conditions in sheep and goats. Open Veterinary Journal, Vol. 3(1): 11-16.

El-Tookhy, O.; Al-Sobayil, F.A. and Ahmed, A.F. (2012): Normal ocular echobiometery of the dromedary camels. Journal of Camel Practice and Research, Vol. 19 No 1, p 13-17.
Fielding, J.A. (2001): The eye and orbit. In: Meire, $\mathrm{HB}$; Cosgrove, DO; Dewbury, KC and Wilde, $\mathrm{P}$ (Eds.), Clinical ultrasound. (2 ${ }^{\text {nd }}$ Ed.), Edinburgh, Churchill Livingstone. PP: 938964.

Gallhoefer, N.S.; Ellison, B.; Maja, R. and Paula, G. (2013): Comparison of ultrasonography and histologic examination for identification of ocular diseases of animals: 113 cases (20002010). JAVMA, Vol 243, No. 3.

Gelatt, K. and Mackay, E. (2005): Prevalence of primary breed related cataracts in the dog in North America. Vet. Opthalmol., 8: 101-111.

Gelatt, K.N.; Gilger, B.C. and Kern, T.J. (2013): Veterinary Ophthalmology: Two Volume Set: John Wiley \& Sons.

Gilger, B.C. and Stoppini, R. (2011): Equine ocular examination: routine and advanced diagnostic techniques. In: Gilger $\mathrm{BC}$, ed. Equine ophthalmology. 2nd ed. Maryland Heights, Mo: Elsevier Saunders; 37-42.

Gonzalez, E.M.; Rodriguez, A. and Garcia, I. (2001): Review of ocular ultrasonography. Vet. Radiol Ultrasound; 42: 485-495.

Hoffmann, I.; Schäffer, E. and Reese, S. (2004): Die sonographische Untersuchung des vorderen Augenabschnittesbeim Kleintier. Teil 2: pathologische Befunde. Tierarztl Prax K; 32: 238-246.

McLeod, D.; Restori, M. and Wright, J. (1977): Rapid Bscanning of the vitreous. Bri. J. Ophthalmol., 61: 437-445.

Mellersh, C.S. (2014): The genetics of eye disorders in the dog. Canine Genetics and Epidemiology 1,3 .

Mettenleiter, E.M. (1995): Sonographic diagnosis (Bmode technique) for the eyes in horses. 1. Methods and normal findings. Tierarztl Prax; 23:481-488.

Osuobeni, E.P. and Hamidzada, W.A. (1998): Determination of sound velocity in the lens of the one-humped camel. Medical Science Research 26:267-269.

Penninck, D.; Daniel, G.B. and Brawer, R. (2001): Cross-sectional imaging techniques in veterinary ophthalmology. Clin Tech Small Anim Pract; 16:22-39.

Potter, T.J.; Hallowell, G.D. and Bowen, I.M. (2008): Ultrasonographic anatomy of the bovine eye. Veterinary Radiology and Ultrasound 49(2): 172-175

Ramirez, S. and Tucker, R.L. (2004): Ophthalmic imaging. Vet. Clin North AmEquine Pract; 20:441-457.

Reef, V.B. (1998): Equine diagnostic ultrasound. Philadelphia, Pennsylvania (WB Saunders Company) $1^{\text {st }}$ Ed. Pages 481- 536.

Rubin, L.F. and Koch, S.A. (1968): Ocular diagnostic ultrasonography. Journal of the American Veterinary Medical Association 153(12): 1706-1716. 
Spaulding, K. (2008): Eye and orbit. In: Pennieck, D and d'Anjou, MA (Eds.), Atlas of small animal ultrasonography. (2 ${ }^{\text {nd }}$ Ed.), Iowa, Blackwell Publishing. PP: 49-89.

Tavana, M. and Peighambarzadeh, S.Z. (2014): Normal ocular ultrasonographic finding in dog. Indian Journal of Fundamental and Applied Life Sciences Vol. 4 (S3), pp. 347350.

Torad, F.M. (2000): Evaluation of some anaesthestic techniques in pet animal under local circumstances. M.V.Sc, surgery, anaesthesiology and radiology. Fac. Vet. Med. Cairo univ.
Whitcomb, M.B. (2002): How to Diagnose Ocular Abnormalities with Ultrasound. Proceedings of the Annual Convention of the AAEP, Vol. 48, Pages 272-275.

Wilkie, D.A. and Colitz, C.M. (2009): Update on veterinary cataract surgery. Current Opinion in Ophthalmology 20(1): 61-68.

Wilkie, D.A. and Gilger, B.C. (1998): Equine diagnostic ocular ultrasonography. In: Rantanen NW, McKinnon AO, eds. Equine diagnostic ultrasonography. Baltimore: Williams \& Wilkins; 637-645.

Williams, L. (2010): Congenital Abnormalities in Production Animals. Vet. Clin. North Am. Food Anim. Pract. 26, 477-486.

\section{التشخيص باستخدام الموجات الفوق صوتية لبعض إصابات العين فى الكلاب}

جمال عبل الناصر رجب ، معد ذكى فتحى

E-mail:mzfhussein83@gmail.com Assiut University web-site: www.aun.edu.eg

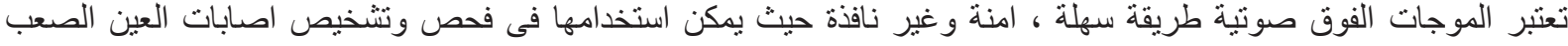

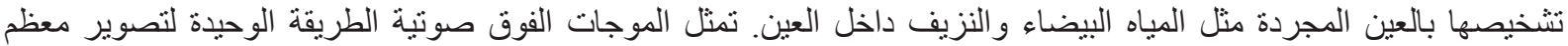

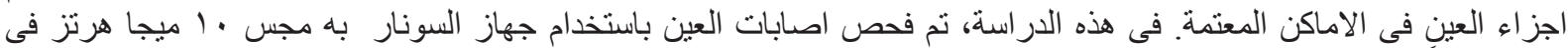

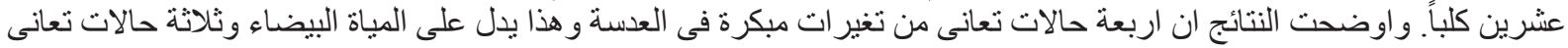

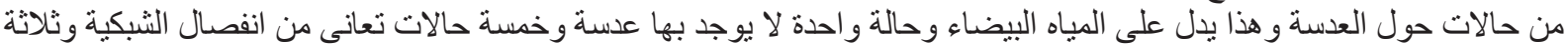

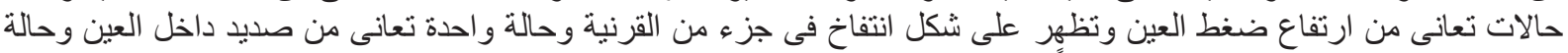

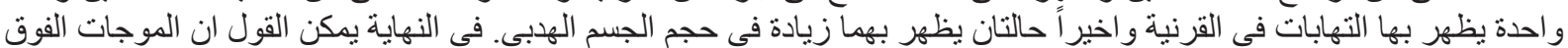

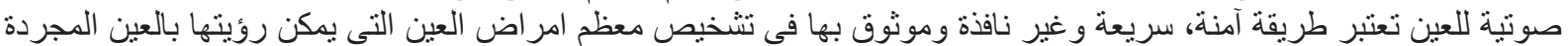

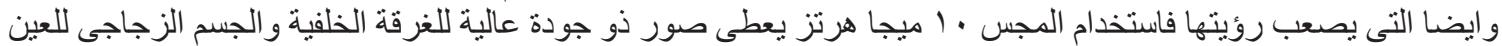

